\title{
The Impact of Social Media on Cultural Adaptation Process: Study on Chinese Government Scholarship Students
}

\author{
Hsu Thiri Zaw \\ School of Journalism and Information Communication, Huazhong University of Science and Technology, Wuhan, China \\ Email: hsuthirizaw@yahoo.com
}

How to cite this paper: Zaw, H. T. (2018). The Impact of Social Media on Cultural Adaptation Process: Study on Chinese Government Scholarship Students. Advances in Journalism and Communication, 6, 75-89. https://doi.org/10.4236/ajc.2018.63007

Received: August 16, 2018

Accepted: September 11, 2018

Published: September 14, 2018

Copyright $\odot 2018$ by author and Scientific Research Publishing Inc. This work is licensed under the Creative Commons Attribution International License (CC BY 4.0).

http://creativecommons.org/licenses/by/4.0/

\section{(c) (i) Open Access}

\begin{abstract}
In the globalization era, social media become more popular in everyone's daily life with its user friendly and effective functions. Social media support the people across the world in communicating, meeting new people, making socialization, sharing knowledge, learning different experiences and interacting with each other instead of distance and separation between persons. Moreover, social media can encourage the increasing of intercultural adaptation level of people who are facing different cultural experiences in new communities. The study shows that people use social media to become more adaptable with the new cultures of the host countries and to preserve their connections with home countries. This paper attempts to find out how social media shape the intercultural adaptation process and bridge the connection with their home countries while they are in new community analyzing on 15 international students who are currently studying in China with the support of Chinese government scholarship program. In-depth interviews using qualitative method are applied in this research. Depending on the analysis result, the discussions are openly stated about the impact of social media in cultural adaptation process.
\end{abstract}

\section{Keywords}

Culture, Social Media, Intercultural Communication, Cultural Adaptation, International Students

\section{Introduction}

It can be said that cultures around the world have their own values, individual traditions, beliefs and norms which can surely make them unique from each 
other. According to Chen \& Zhang (2010), due to the convergence of new media and globalization, has shrunk the world into a much smaller interactive field. Moreover, during the globalization era, the number of people who go abroad for studying, doing business and so on has become significantly increased.

Due to the different culture and community practices, the sojourners always face culture shock when they first get to the host countries. Therefore, they use different methods and resources to lessen the shock and to be adjustable in the new culture and community. Adelman (1988) mentioned that it is widely accepted that the social outlook of human assistance is necessary in the process of cross-cultural adaptation in terms of social support from people from home country and host country with new culture. Those kinds of support come from the various ways; however, social networking technologies or social media are the most effective way for sojourners in communication and learning new culture. Social networking technologies help people to communicate in different modes of geographic location and time.

Social media connect people across space and time and allowing them to find like-minded communities and participate creatively in public life as never before. Moreover, social media promote the interconnectedness and interdependence of our culturally diverse world. Media for social interaction allow for people to communicate and engage with information that is quickly accessible on the Internet. In recent years, social media have become more popular in daily activities and routines of the people as the number of internet users become higher. While social media provide a common way of linking people together through knowledge, behavior, and attitudes, a sense of belonging to a greater social network other than one's own local community is significantly established. The social media support the effective way to connect a diversity of people, traditions, opinions and places with each other across the world without being restricted by the limitations of time and distance (Sawyer \& Chen, 2012).

Based on such kind of multi functions, social media become important for sojourners in settling down the stress and depression from the physical and geographical separation from the previous community in the home country. The sites can help to build a new relation in the host culture and also become the most important factor for the issue of cultural adaption of sojourners (Church, 1982). Therefore, it is so significant that social networking sites provide the chances for the sojourners to be familiar with both old relations with the community in the home country and also new one in the host community.

Alan Dershowitz's famous statement shows that internet knows no borders. With the effect of social media, geographical borders are overcome by individuals. It can be obviously seen that two persons from different places with different cultures are now sharing the similar meanings. Throughout the intercultural adaptation, social media are widely used for learning about their host countries, implement the relationships and stay connected with the events in their home countries. Communication and interaction are two main factors that have impact how social media affect intercultural adaptation. 
As Steger (2009) mentioned,

"Due to the thrust of new media, the global trend creates new social networks and activities, redefines political, cultural, economic, geographical and other boundaries of human society, expands and stretches social relations, intensifies and accelerates social exchanges and involves both the micro-structures of personhood and macro-structures of community."

When Sawyer \& Chen (2012) analyzed how international students apply social media for their intercultural adaptation, they found that social media could create a community for international students to connect with people not only from their home but also from the host countries. Therefore, it can absolutely support them having a strong personal relationship and establish a sense of adaptation to the culture of host country. Using social media significantly supports international student to overcome barriers of cross cultural communication in the stage of intercultural adaptation. It is found out that sojourners start relying much on social media in the beginning stage of living in the host country because of the culture shock and connection with the people from their home country for getting rid of the sense of homesickness and building a new comfort zone in the different community. After the initial stage with the time passing by, their use of social media has been changed to interaction with the people from the host culture for the adaptation of the new culture (Sawyer \& Chen, 2012).

Croucher (2011) attempted to figure out a theoretical model through the integration of cultivation theory and ethnic group vitality to shape the connection between social networking and cultural adaptation. He illustrated two statements and the first one is that the use of social networking sites has impacts immigrants' interaction with the dominant culture during cultural adaptation. And the second statement is that the use of social networking sites will affect immigrants' in-group communication during cultural adaptation.

There are so many researches in finding out the relation between the social network and cultural adaptation of international students or sojourners based on different regions of the world. However, it can be said that China is the significant region in term of supplying social networking sites. The most popular social networking sites around the world such as Facebook, Twitter, Instagram, YouTube and Google products are blocked in China and so the international students who first come to China face big culture shocks in terms of social media. Therefore, this study focus on the cultural adaptation process and social media effect on international students who are studying in China for their degrees. The study will show how social media has impact on cultural adaptation of international students in host country and also how it can maintain the connections of international students between their host countries and home countries.

\section{Theoretical Background}

\subsection{Culture}

According to Edward Burnett Tylor, culture is a complex whole which includes 
knowledge, belief, art, morals, law, custom and any other capabilities and habits acquired by man as a member of society (Tylor, 1871). Therefore, it can be said that culture and communication is a related phenomenon that could express that culture is a communication process and communication is a culture process. The more different between high context culture and low context culture, the more impacts have on cultural representation on electronic media. It means that culture orientations have impacts on the choices of users on social network applications.

Power distance, individualism/collectivism, masculinity/femininity, uncertainty avoidance and long-term/short-term orientation are Hofstede's cultural dimensions (Itim, 2009). Power distance is defined as under the situation when the less powerful members of organizations and institutions accept and expect that power is distributed unequally. This represents inequality but defined from below, not from above. The various degrees that can affect the individual and the groups is individualism and collectivism. On the individualist side, it is found that societies in which the ties between individuals are loose that everyone is expected to look after him or herself and his or her family while it is found out that people from birth onward are integrated into strong, cohesive in-groups, often extended families that continue protecting them in exchange for unquestioning loyalty on the collectivist side. The method showing the distribution of roles between the genders such as assertive and competitive and caring and nurturing is referred as masculinity and femininity. The studies by IBM showed that a) women's values differ less among societies than men's values and b) men's values from one country to another contain a dimension from very assertive and competitive and maximally different from women's values on the side, to modest and caring and similar to women's values on the other.

Uncertainty avoidance relates to the society's tolerance for uncertainty and ambiguity. Due to inner nervous energy, people from uncertainty avoiding countries are also more emotional and motivated. However, uncertainty accepting cultures are more tolerant of opinions different from what they are used to such as they try to have as few rules as possible. The final one of cultural dimensions by Hofstede (2001) is long-term and short-term orientations that shape the focus and values of a culture. Both of positive and negative values of this dimension can be found in the teachings of Confucius, the most influential Chinese philosopher who lived around 500 B.C, however, the dimension also applies to countries without a Confucian heritage.

The French sociologist, Gabriel Trade first mentioned about the Diffusion of Innovation Theory in 1903 and then that theory was followed by Ryan and Gross in 1943 who discussed about the adopter categories that were later used in the current theory by Everett Rogers. Katz (1957) is also credited for first introducing the notion of opinion leaders, opinion followers and how the media interacts to influence these two groups. The Diffusion of Innovation theory is often regarded as a valuable change model for guiding technological innovation where the innovation itself is modified and presented in ways that meet the needs 
across all levels of adopters. It also stresses the importance of communication and peer networking within the adoption process. In general term, the diffusion of innovation theory refers to the process that occurs as people adopt a new idea, product, practice, philosophy and so on.

\subsection{New Media}

Chen (2007) stated that the influence of digital or new media on the society is illustrated in terms of the cognition, social effect and a form of aesthetics. Throughout the world, according to the need of new media, new social networks and activities are created in reshaping the lines of human society in terms of politics, culture, economic and geography. Steger (2009) mentioned that new social media can accelerate social changes involving in the structure of community. New media is identified into five characteristics and they are digitality, convergency, interactivity, hyperactivity, hypertextuality and virtuality (Chen \& Zhang, 2010).

The most significant feature of new media is digitalization among those five characteristics. New media applies all kind of mathematical operations for dematerializing media text by converting data from analog into digital form. The convergency in new media is defined as the way that new media converges the forms and functions of media, electronic communication and media and it is clearly seen in the emergence of the Internet. The interactivity is mentioned as the function between users and the system in terms of use of information resources. New media introduce hypertextuality that information can move around freely and interconnect. New media created cyberspace which make people to generate virtual experience and reality. The form and content of messages can be influenced by the new media. Moreover, new social media has impacts on how people understand each other in the process of human communication in the specific cultural and traditional group.

As stated by Georgetown University, 2010, new social media means that everyone is a publisher and everyone is a critic. Therefore, it is so significant that online contexts in social media are interactive dialogues that can show from different points of view. People communicate with others by using different networks which new social media provide. People nowadays, use social media in terms of gaining knowledge, learning about different opinions, perspectives of issues, topic and events and also interacting with others. Moreover, new social media is mainly used for socializing which is type of media that make people include in conversations and online talks without being face-to-face with other participants.

Social media of these days can create a place where people throughout the world can stay in touch and more connected despite of the distance, boundaries, culture and so on. Chen (2012) stated that new social media such as Facebook, blogs, MySpace, YouTube, Twitter and Instagram have allowed people from every single place of the world to represent themselves in their significant ways and stay touched in technological world. 


\subsection{Intercultural Communication}

Intercultural communication is the process of interaction between people from different cultures and different communities. According to Karlfried Knapp in the book of "Encyclopedia of Communication Theory" (Littlejohn \& Foss, 2009), intercultural communication is referred as the interpersonal interaction between the people from diverse groups which are different from each other under the different forms of knowledge and symbolic behavior in terms of cultures, norms, traditional practices and so on. Therefore, it can be said that the people's behavior, communication, and concepts from different countries and communities have impacts on intercultural communication. Culture hugely affects communication in significant way.

It can be clearly seen that intercultural communication appeared since the beginning of history. In ancient times, people travel around the world and made long-distance journey. From that point, people settled down in different regions as different communities. Researchers always attempt to find out the traces the prehistoric movements and gestures of people by using analysis of their characteristics, language, families, blood types and so on. Differences and diversity of people in cultural norms, values and perceptions can be assumed as a quiet and invisible root of misunderstanding and misconceptions in different regions and communities. The problems are mostly seen when cultural verbal and nonverbal meanings are affected to the other people with different cultures.

Hall showed the methods for understanding of cultural differences with the Information Systems Theory (Primary Message Systems). The Information Systems Theory (1959) labels human activities into ten main message systems and they are 1) interaction, 2) association, 3) subsistence, 4) bisexuality, 5) territoriality, 6) temporality, 7) learning and acquisition, 8) play, 9) defence and 10) exploitation. Hall mentioned that interaction is situated in the center place of the culture world and it is also the complex and being at the most institutionalized communal life sustained by living beings belongs to humans.

Neuliep (2014) stated that intercultural communication is the communication between people of different cultures and ethnicities. Moreover, it is also symbolic sign of intercultural contact that organize an open and respectful interaction among individuals, groups and organization with different cultural beliefs and background. Intercultural communication can improve mutual understanding of diverse culture and practices and foster the equality among the different things and also enhance creative process. It is so significant that new media can make new culture increase in human society and the obvious part is in the process of intercultural communication.

\subsection{Cultural Adaptation and Social Media}

Bennett (1977) who is a cross-cultural writer mentioned cultural adaptation as a process of "transition experiences". He defined cultural adaptation as the responses to the sharping changes in life situations that handle the "tensions and 
anxieties we face whenever change threatens the stability of our lives". According to Weaver (1993), in the adaptation process, the most significant thing, "cultural shock" is generally used as the term "cultural adjustment stress". One of the cultural trainer recently advised that the expression "being effective abroad" is surely needed to substitute the necessary survival factors of the cross-cultural construct (McCaffery, 1986).

According to Kim (2001), the multicultural community is enlarged along with the practices of sojourners, immigrants and other people who can make the shift from one specific culture to another, so it can be surely said that intercultural studies totally focus on the interactions between people from different cultural backgrounds. Gudykunst (2003) mentioned the adaptation as a "dynamic process by which individuals, upon relocating to an unfamiliar cultural environment, establish or reestablish and maintain a relatively stable, reciprocal and functional relationship with the environment."

According to Stewart \& Mendenhall (1991), U-curve adjustment theory by Sverre Lysgaard, a Norwegian sociologist in 1955, shows that the important and considerable four stages can be seen and they are honeymoon, crisis, adjustment and biculturalism when it draws connections intercultural adaptation to social media use. In honeymoon stage, people will face the initial relaxation for being in different country. After that, people start meeting the crisis stage which includes resentment and sadness for residing in a totally different culture and community. Later, they try to get adjustment and recovery and after that stage, the last stage "biculturalism" is the one which is the stage of fully adjustment and adaptation with the new culture and society.

Based on those four stages, research showed that social media has a social, physical and cultural influence on cultural adaptation. According to Elola \& Oskoz (2009), the use of social media especially blogging and vlogging can have positive impacts on the intercultural relationship and also improve the degree of participants' intercultural communication competence. It is significant that the information used and shared in the social media will surely have impacts either positively or negatively to the improvement of intercultural relationships in the virtual community by creating its own network of personal connection (Donath \& Boyd, 2004; Ellison, Steinfield, \& Lanmpe, 2009).

From the process of sending messages to posting on social apps, they are ongoing uses of digital media that shows all the channels that make online personal communications possible (Wooley, 2013). Chen (2007) mentioned that the effect of digital or social media is illustrated in the points of cognition, social effect and a starting form of aesthetics. Moreover, according to Piechota mentioned by Seyfi \& Guven (2016), social media plays a significant sector in building new forms of multicultural interactions apart from being regarded as an important tool in the sharing of messages. Relating to those findings, social media and intercultural communication are aspects that have impacts and outline each other. Moreover, regarding to that concept, it can be significantly seen that an adjustment and sense of community appear along with the use of social media in in- 
tercultural communication. In cultural adaptation, adjustment is one of the most important factors and this process is influenced by social media. According to Sawyer \& Chen (2012), the adjustment process of migrants to the host culture in America becomes improved with the use of social media.

\section{Methodology}

For analyzing the impact of social media in the process of cultural adaptation among international students, the researcher made in-depth interview with 15 international students who are studying master degree and $\mathrm{PhD}$ degree in Huazhong University of Science and Technology, Wuhan City, Hubei Province, People Republic of China. In order to get more specific data, the research is based on qualitative research method and used investigative questions by talking with them, questioning in detail and figuring out the analysis based on their answers. Apart from the specific questions, the researcher made more detailed questions based on their opinions and comments. Moreover, the researcher met the participants more than once to discuss about the questions and make sure in getting exact information and analysis in the research. The participants are from Asia, Africa and even in some Pacific island countries and most participants have never been to China before. The participants are from Asia, Africa and even in some Pacific island countries and most participants have never been to China before they came to China for study and become the students of Huazhong University of Science and Technology. According to the answers they mentioned in the interview, it can be found out that some participants have never known about Chinese culture and traditions before they have registered as the students in China.

The interview was designed to figure out how social media effect on their daily lives in the new culture of host country and maintain the relation the connections to the communities in the home countries.

Analyzing about the impact of social media in the process of international students' cultural adaptation, the questions are based on how their adjustment to verbal and non-verbal communication in the host country, what their culture shocks are, what they learnt about new culture using social media, how social making on social media help them to have adaptation to the new culture of the host country and so on. Unlike the research which analyzed about other regions, China is somehow significant in social media usage because there are blockages to some popular social networking sites in most of the countries around the world such as Facebook, Twitter, Instagram, Google, Youtube and so on. Therefore, the questions also focus on the shocks regarding the use of social media in China for international students because of censorship system and language barriers when they use Chinese social networking sites with Chinese language.

\subsection{Data Collection}

For data, the researcher collected data making in-depth interviews from 15 in- 
ternational students who are currently studying in Huazhong University of Science and Technology under the support of Chinese government scholarship program. According to more specific data collection, the data which showed that their visits (or) stays to other countries except China were also collected. The researcher also figured out the questions that could show the significant views of each international student concerning the impact of social media on cultural adaptation.

The Table 1 below is shown the brief description of participants in the research.

\subsection{Data Analysis}

Depending on the questionnaires, it can be divided into three sectors; 1) culture shocks (the things when the participants meet when they get to China), 2) Adjustment via socialization (how participants have tried to socialize in the new community) and 3) adaptation via social media (how participants use social media to get adaptation in the new culture of the host community).

\subsubsection{Facing New Things as Culture Shocks}

According to the anthropologists Kalervo Oberg and George Foster in the late 1950s, culture shock was a medical condition describing feelings of disorientation following entry into a new culture, feelings often so strong as to degenerate into physical symptoms. By seeing those definitions, culture shock is usually regarded as an affliction that comes from the individual as an occupational illness and also with the impact of a falling piano (Winkelman 1994). On the other hand, from being cultural point, culture shock is simply frustration reaction syndrome. The participants' answer in the interview about their culture shocks which they

Table 1. Brief description of participants in the research.

\begin{tabular}{ccccc}
\hline No. & Home country & Education level & Sex & Cross-cultural experience \\
\hline 1. & Palestine & $\mathrm{PhD}$ & $\mathrm{M}$ & One time to Indonesia \\
2. & Sri Lanka & $\mathrm{PhD}$ & $\mathrm{M}$ & Three times to 3 different apart from China \\
3. & Ethiopia & $\mathrm{PhD}$ & $\mathrm{M}$ & Three times to 3 different apart from China \\
4. & Ghana & $\mathrm{PhD}$ & $\mathrm{M}$ & Several times to many different countries \\
5. & Nepal & $\mathrm{PhD}$ & $\mathrm{M}$ & Two times to two different countries \\
6. & Senegal & $\mathrm{PhD}$ & $\mathrm{M}$ & Several times to many different countries \\
7. & Malawi & $\mathrm{PhD}$ & $\mathrm{M}$ & Several times to many different countries \\
8. & Maldive & $\mathrm{PhD}$ & $\mathrm{F}$ & Several times to many different countries \\
9. & Myanmar & $\mathrm{PhD}$ & $\mathrm{M}$ & \\
10. & Fiji & Master & $\mathrm{M}$ & Several times to many different countries \\
11. & Tonga & Master & $\mathrm{M}$ & Several times to many different countries \\
12. & Malawi & Master & $\mathrm{M}$ & \\
13. & Myanmar & Master & $\mathrm{M}$ & Several times to many different countries \\
14. & Namibia & Master & $\mathrm{F}$ & Three times to three different countries \\
15. & Mauritius & Master & $\mathrm{M}$ & Several times to many different countries \\
\hline
\end{tabular}


face when they get to China could highlight about how they have to struggle in their daily lives in the new community.

"Travelling to a new culture can mean seeing things on the menu that you never even knew you could eat. For instance, in China and in many Chinese restaurants around the world, chicken feet are served regularly and are a delicacy here in China." (Interviewee J)

"I remember feeling helpless and frustrated at my inability to understand anything. Everything took extra time to figure out. I felt anxiety about asking directions because I couldn't understand what the other person was saying. At times I just didn't want to go out because it took too much effort." (Interviewee $\mathrm{K})$

"When I first came to China, I was surprised to learn that many of the bathrooms were actually squatting toilets. I admit, at first these differences in the toilet do seem a bit strange but after a while you barely notice." (Interviewee K)

"I am really surprised that blocked on social media, controlled of power voltage, elder people working in odd jobs in China.” (Interviewee $\mathrm{H}$ )

"Totally shocking for me. Because I'm from the place where I rarely find any people without religion in the whole world either through news or through social media. But here in china, if you ask somebody about the religion, they reply to you as they don't have any religion. Don't know why?" (Interviewee E)

"You will almost always notice people crowding at the service window at the bus station or a line with people cutting in line. Chinese people have a mentality that they need to be first in line to get what they need due to past experiences. It isn't true in all places in China although, but you may be surprised with this occasion while traveling around China." (Interviewee J)

"I never have an experience of big problems concerning with culture shocks though. I still have very rare and only one of my uncomfortable experience of culture shock is at China concerning with language barrier. Since most of Chinese people don't speak English or even a person who can speak English don't want to speak English a lot." (Interviewee M)

\subsubsection{Adjustment via Socialization in Various Communities}

For the adjustment using socialization with local people in China is one of the most popular ways for expats who are living China. Some international students are socializing not only with local people but also with students from other communities for their difficulties and culture shocks in China. On the other hand, according to the participants, social media sites can help them to adjust their language barriers in daily activities.

"I wouldn't really call is socializing, as most encounters with the Chinese locals are on the borders of just either small talk, or when you need help from them in terms of translations, directions etc. Without prejudice, they are very sociable people, however, it all depends on the nature of a person." (Interviewee J)

"Everyday I meet my Chinese friends in the office where I do my research 
work, but I got very rare talk with the Chinese friends due to the language problem. Regarding Chinese locals, I meet and try to talk with then like once a week during my indoor tour in the city and in the market place when I need to buy something." (Interviewee E)

"In the university that I study, most of them are from different community and societies that the locals. So I find very variant nature in them according to their born city. Like people from big cities tries to communicate in other to learn English but the people from other village or small cities rarely express and share their talks with others." (Interviewee E)

According to the participants' answers, it might be clearly seen that some international students mostly socialize with international students because of the language barriers. However, they become friends with Chinese locals through social media. Mostly, they make socialization because of the stress and culture shocks which they face in the new community with different culture. It also shows that some students even learnt some cultures of hots country from socialization with locals. Moreover, respondents in the research mentioned about the verbal communication which are somehow difficult for them.

"I have to speak real slow and stopped using jargons or slangs that would necessarily be accepted as the normal way to converse in the other countries that I have been to. I have also had to make changes in a sense to use certain words that are seen/perceived to be offensive, when they are not." (Interviewee J)

"I am trying to learn Chinese language communicating with Chinese people and also made some friends who want to make friends to learn English language. Mostly I communicate with them using language translation software and sometimes with gestures." (Interviewee E)

\subsubsection{Cultural Adaptation via Social Media}

Under the part of the cultural adaptation of international students by using social media, it can be divided into two parts. First one is how social media support the international students in communicating with the home country or their community in China and the second one is how social media can help them adapt the new culture while living in the new community. Moreover, some respondents in research use social media not only for social making but also for removing their loneliness and boredom.

"Yes, I use social media a lot. It is due to lack in the number of friends to hang out with and of course due to the absence of family, the only way is to spend time on social media." (Interviewee E)

"Yes, I use social media here in China much more time than I use at home because sometimes am feeling very lonely." (Interviewee F)

In the research, the participants openly mentioned that social media can help them to communicate with their home countries and also get in touch with the people in their respective communities in China. Social media supports the most as the effective and economical way for international students to keep in contact with their families and friends in their home countries. Moreover, social media 
become the most basic requirement for getting information not only from the home countries of the international students but also about China while they are staying in China.

"I fully communicate with my community with social media." (Interviewee B)

"It was very easy to get in touch with my community because of the social media mostly WeChat that I use often to communicate and its very fast and economical media. It makes you communicate in a rapid way by making groups of my own community and friends so that to share in formations very easily." (Interviewee E)

"Social media do help to connect people together in all time and social media is an easy mode of communicating than voice mode. Social media is more attractive and communicate in different language." (Interviewee B)

"Of course, WeChat has helped me through to get in touch with my own community in China as we can't access other apps like Facebook and Viber which most of our majority people in back home using." (Interviewee I)

"Social media help me to get easily in contact with my own community and I really appreciate that means a lot. I am feeling very close to my country mates because of social media." (Interviewee $\mathrm{F}$ )

"Helped ease communication with my own community when I don't have a phone and this means a lot to me." (Interviewee $\mathrm{K}$ )

"It has helped me a lot. I do get a lot of invaluable information through social media. It means a lot to me and brings about convenience because I am assured to find almost most of the basic information that I need for my day to day survival in China." (Interviewee G)

Apart from helping to communicate with the home country and their own respective communities in China, social media support international students to adapt the different culture while living in new community. The respondents mentioned that they learnt many things about China from social media not only before they come to China but also after they arrive to China especially Chinese culture and tradition. Although it would have taken more time to really grasp and comprehend the new culture in China for international students, social media make it much easier than it would have been otherwise. In the community with language barriers and other difficulties, respondents use social media as a guide for their daily activities especially buying stuffs online, booking for some events and celebrations, arranging trip plans, making friends and even sharing the idea in group or making study groups.

"Some apps in social media has enabled many domestic entrepreneur and infused different countries' culture with an amazing richness of creativity." (Interviewee $\mathrm{K}$ )

"The social media like WeChat in China, we can buy any and everything, so this kind of social media help the people to living and adapt in China." (Interviewee A)

"Some things are generally not explained yet is somehow expected to be like 
the norm of the society. But these things are generally learnt from social media, due to perhaps the stigma of actually discussing them out loud and openly." (Interviewee J)

"Yes, I am because I love reading experiences that users sharing on social media. That helps me to understand china and its culture." (Interviewee F)

"Social media has enabled me to know more of what I already know such as interesting and unknown facts about China, especially interesting places and where to buy delicious food or buy clothes, also updates me with what is currently happening in China." (Interviewee K)

\section{Conclusion}

The result of this research points out how social media shape the cultural adaptation of international students who are studying in China between their home countries and host countries. Throughout the study, the participants overcame culture shocks what they face as soon as they arrive to China mostly using social media not only for socializing but also for learning new things in their host countries. They infer that the interactions and conversations through the social media can make them strengthen to adapt the new culture in the host countries by overcoming the new challenges in the new community and building a sense of community with different cultures.

It is widely accepted that adjustment is the basic fundamental factor in cultural adaptation, and social media are the most influential support in this process for international students. Before they arrive in China, the respondents talked that they used some social media to know more about China and its people and also Chinese cultural practices for their daily activities. Therefore, this research can show that social media play as one of the best methods for interaction and conversation for international students to keep in touch with their home countries and learn about intercultural practices and experiences.

Furthermore, in the research, the respondents mentioned about using some Chinese social media applications to understand Chinese cultural norms and practices. The participants acknowledged that the information and learnings through the social media could change the stereotypes and biases which they had known before coming to China into the positive impression and different opinions for international students. The Chinese social media have changed the students' views regarding the information and comments that they used to think about China before their visit. Social media can support the international students in not only helping to get cultural adaptation but also for getting academic-related information and interact with professors easily. Therefore, some respondents mentioned that they sometimes feel worried about themselves to become social media addicts because the amount of time they are spending in social media platforms has already increased due to its user friendly and helpful functions for them.

The research analyzes about how many social media have impacts on the cultural adaptation of the students from Huazhong University of Science and 
Technology in the new community in China. It can be seen that the previous researches were mostly about the cultural adaptation process of students from some specific countries who are studying in China or students who are studying in some other European countries under some other scholarship programs. This research figured out the result based on the data collected from the students from different countries around the world who are currently staying in China. Though the research is based on the students in only one university in China, the participants in the research are from Asia, Africa and some Pacific island countries so it can be strongly said that there is diversity in data collection process.

However, there are some facts in this research are limited. The first thing is that the researcher only interviewed 15 students who are studying in Huazhong University of Science and Technology, Wuhan City, Hubei Province in China due to time limitations. Hence, it is strongly suggested that interviewing more students in some other universities throughout the city or province or even the country, China for the further research to get more comprehensive aspects about the impact of social media in cultural adaptation from various and diverse community. Moreover, the interviews to not only students but also for working people and migrants in China are suggested for more specific research about the use of social media for intercultural adaptation.

\section{Acknowledgements}

I would like to thank to all my professors and colleagues who always encourage me to carry out this research paper. Moreover, I would like to show my sincere gratitude to the participants who actively helped me and answered my in-depth interview questions regardless of their busy schedules.

\section{Conflicts of Interest}

The authors declare no conflicts of interest regarding the publication of this paper.

\section{References}

Adelman, M. B. (1988). Cross-Cultural Adjustment: A Theoretical Perspective on Social Support. International Journal of Intercultural Relations, 12, 183-204. https://doi.org/10.1016/0147-1767(88)90015-6

Bennett, K. C., \& Ahammer, M. I. (1977). Toward a Social Deficit Model of Ageing. Australian Journal of Social Issues, 12, 3-15. https://doi.org/10.1002/j.1839-4655.1977.tb00583.x

Chen, G. M. (2007). Media (Literacy) Education in the United States. China Media Research, 3, 87-103.

Chen, G. M. (2012). The Impact of New Media on Intercultural Communication in Global Context. China Media Research, 8, 1-10.

Chen, G. M., \& Zhang, K. (2010). New Media and Cultural Identity in the Global Society. In R. Taiwo (Ed.), Handbook of Research on Discourse Behavior and Digital Communication: Language Structures and Social Interaction (pp. 801-815). Hershey, PA: Idea Group Inc. https://doi.org/10.4018/978-1-61520-773-2.ch051 
Church, A. T. (1982). Sojourner Adjustment. Psychological Bulletin, 91, 540. https://doi.org/10.1037/0033-2909.91.3.540

Croucher, S. M. (2011). Social Networking and Cultural Adaptation: A Theoretical Model. Journal of International and Intercultural Communication, 4, 259-264. https://doi.org/10.1080/17513057.2011.598046

Donath, J., \& Boyd, D. M. (2004). Public Displays of Connection. BT Technology Journal, 22, 71-82. https://doi.org/10.1023/B:BTTJ.0000047585.06264.cc

Ellison, N. B., Lampe, C., \& Steinfield, C. (2009). Social Network Sites and Society: Current Trends and Future Possibilities. Interactions, 16, 6-9. https://doi.org/10.1145/1456202.1456204

Elola, I., \& Oskoz, A. (2009). Blogging: Fostering Intercultural Competence Development in Foreign Language and Study Abroad Contexts. Foreign Language Annals, 41, 454-477. https://doi.org/10.1111/j.1944-9720.2008.tb03307.x

Georgetown University (2010). Bridging Babel: New Social Media and Interreligious and Intercultural Understanding. Washington DC: Georgetown University.

Gudykunst, W. B. (2003). Cross-Cultural and Intercultural Communication. Thousand Oaks, CA: Sage Publications, Inc.

Hofstede, G. (2001). Culture's Consequences: Comparing Values, Behaviours, Institutions and Organizations across Nations (2nd ed.). Thousand Oaks: Sage Publications, Inc. http://doi.org/10.1002/j.2162-6057.1993.tb00711.x

Itim International (2009). Geert Hofstede Cultural Dimensions. http://www.geert-hofstede.com/

Katz, E. (1957). The Two-Step Flow of Communication: An Up-to-Date Report on a Hypothesis. Public Opinion Quarterly, 21, 61-78. https://doi.org/10.1086/266687

Kim, Y. Y. (2001). Cross-Cultural Adaptation. Oxford Research Encyclopedias.

Littlejohn, S. W., \& Foss, K. A. (2009). Encyclopedia of Communication Theory. Thousand Oaks, CA: SAGE Publication Inc. https://doi.org/10.4135/9781412959384

McCaffery, P. (1986). Sociology. SAGE Journals, 20, 654-655.

Neuliep, J. W. (2014). Intercultural Communication: A Contextual Approach (6th ed.). Thousand Oaks, CA: SAGE Publication Inc.

Sawyer, R., \& Chen, G. M. (2012). The Impact of Social Media on Intercultural Adaptation.

Seyfi, M., \& Guven, D. (2016). Influence of New Media on Intercultural Communication: An Example of an Erasmus Student.

Steger, M. B. (2009). Globalization: A Very Short Introduction. Oxford: Oxford University.

Stewart, B. J., \& Mendenhall, M. (1991). The U-Curve Adjustment Hypothesis Revisited: A Review and Theoretical Framework. Journal of International Business Studies, 22, 225-247. https://doi.org/10.1057/palgrave.jibs.8490301

Tylor, E. B. (1871). Primitive Culture (Vol. 1). Mineola, NY: Dover Publication.

Weaver, W. T. (1993). Anatomy of a Creative Problem Solving Meeting. The Journal of Creative Behavior, 27, 236-269. https://doi.org/10.1002/j.2162-6057.1993.tb00711.x

Winkelman, M. (1994). Culutral Shock and Adaptation. Journal of Counseling and Development, 73, 121-126.

Wooley, S. (2013). Constantly Connected: The Impact of Social Media and the Advancement in Technology on the Study Abroad Experience. The Elon Journal of Undergraduate Research in Communications, 4, 40-50. 